\title{
Impressive abrasion rates of marked pebbles on a coarse-clastic beach within a 13-month timespan
}

\author{
Duccio Bertoni ${ }^{\mathrm{a}, *}$, Giovanni Sarti ${ }^{\text {a }}$, Edoardo Grottoli ${ }^{\mathrm{b}}$, Paolo Ciavola ${ }^{\mathrm{b}}$, Alessandro Pozzebon ${ }^{\mathrm{c}}$, \\ Gabor Domokos ${ }^{\mathrm{d}}$, Tímea Novák-Szabó ${ }^{\mathrm{d}}$ \\ a Dipartimento di Scienze della Terra, Università di Pisa, Via S. Maria 53, 56126 Pisa, Italy \\ b Dipartimento di Fisica e Scienze della Terra, Università di Ferrara, Via Saragat 1, 44122, Ferrara, Italy \\ c Dipartimento di Ingegneria dell'Informazione e Scienze Matematiche, Università di Siena, Via Roma 56, 53100 Siena, Italy \\ ${ }^{\mathrm{d}}$ Department of Mechanics, Materials and Structures, Budapest University of Technology and Economics, Müegyetem rkp. 1-3, K261, Budapest, 1111, Hungary
}

\section{A R T I C L E I N F O}

\section{Article history:}

Received 2 August 2016

Received in revised form 12 September 2016

Accepted 21 September 2016

Available online 22 September 2016

\section{Keywords:}

Abrasion rate

Pebble

Coarse-clastic beach

Beach nourishment

Coastal management

Marina di Pisa

\begin{abstract}
A B S T R A C T
In this paper the abrasion rate on a coarse-clastic beach was evaluated by calculating the volume loss recorded on indigenous pebbles within a 13-month timespan. The experiment was carried out at Marina di Pisa (Italy) on an artificial beach that was built to counteract the erosion processes affecting this sector of the coast. A total of 240 marble pebbles (120 rounded and 120 angular) were marked using the RFID technology and injected on the beach. The volume loss measured after consecutive recovery campaigns was progressively increasing, reaching the maximum value after 13 months ( $61 \%$ overall). The average volume loss is consistent between rounded and angular pebbles at any time (59.3\% and 64.2\% after 13 months respectively), meaning that the roundness is not a primary control factor on abrasion rate. The pebbles that did not reach such abrasion rates after 8 and 10 months (volume loss less than 20\%) were found at heights equal or greater than $2 \mathrm{~m}$ above mean sea level, on the crest of the storm berm that formed during the strongest storms. This implies that the highest wearing is achieved in the lower portion of the backshore, which is also the area that underwent major topographic modifications. Here, sea water action might also exert chemical influence on the pebbles, adding to the mechanical abrasion. The main result of this research, indicating an impressive volume loss on beach pebbles in a short timespan, could be of key importance for coastal managers. The optimization of coarse sediment beach nourishments is also relevant, taking into right consideration that the volume loss due to sediment abrasion might exceed $50 \%$ of the original fill volume just after 1 year in the most dynamic portion of the beach.
\end{abstract}

(c) 2016 Elsevier B.V. All rights reserved.

\section{Introduction}

Since the early stage of the last century, sediment abrasion has always been a subject that raised interest from the scientific community. According to Marshall (1927), abrasion "is the mere effect of pebble rubbing against pebble"; this process is responsible for size reduction of sedimentary particles and also affects their shape and roundness (Russell, 1939). The loss of volume among beach pebbles was investigated in many ways and different causes of this process have been identified. Initially, laboratory studies were preferred: steel drums and tumbler barrels charged with heavy loads of sediments and different kinds of water (sea water, distilled water, dioxane) were adopted in order to define the main factors accounting for pebble abrasion (Marshall, 1927; Russell, 1939; Bigelow, 1988).

* Corresponding author.

E-mail addresses: duccio.bertoni@for.unipi.it (D. Bertoni), sarti@dst.unipi.it (G. Sarti), grtdrd@unife.it (E. Grottoli), cvp@unife.it (P. Ciavola), alessandro.pozzebon@unisi.it (A. Pozzebon),domokos@iit.bme.hu (G. Domokos), tszabo@szt.bme.hu (T. Novák-Szabó).
Later, laboratory tests and field experiments focused on the interaction between indigenous beach materials and tracer pebbles (exotic pebbles with color and texture dissimilar to the native ones) were also used (Latham et al., 1998; Dornbusch et al., 2002; Dornbusch et al., 2003). Lately, field tests with native or fill material are preferred in order to have a real case scenario of volume loss of beach sediments and to estimate the durability of gravel nourishments. Dickson et al. (2011) and Bertoni et al. (2012a) adopted the RFID technology to mark native pebbles on coarse-clastic and mixed beaches, experiencing significant recovery rates (about 50\%) for the experiment periods. Higher recovery rates (over 70\%) were recorded by Chen and Stephenson (2015) using abrasion baskets made of steel mesh. Pebble abrasion was first investigated along rivers (Lewin and Brewer, 2002): in this environment, abrasion is a result of the combination of different physical processes (e.g. collisions, friction) and some authors have already proposed a mathematical model to predict the evolution of shape and size of particles during the abrasion process (Domokos and Gibbons, 2012; Szabò et al., 2013). A similar model is still missing for beach environments, especially to predict 
the evolution of fill material during the planning stage of gravel nourishment. According to Nordstrom et al. (2008), periodic nourishment is required in all beach nourishment operations conducted on eroding shores, but it may be required more frequently on some particular kinds of gravel beaches because of the high rates of loss through abrasion. Thus, the precise estimation of loss rate of fill material is crucial. The aim of the paper is to evaluate the abrasion rate (here defined as volume loss per unit time) of individual marked pebbles on a real setting, within certain timespans, taking into consideration the possible differences between angular and rounded pebbles. Since beach filling using coarse sediments is a practice frequently adopted to protect coastal areas and restore eroded beaches, it is of paramount importance to understand the time required to smooth the angular pebbles and bring the pebbles to a grain-size that is favorable for tourism purposes. As a consequence, the byproduct of this experiment might be of great impact for coastal managers because a considerable abrasion rate would lead to a fast volume reduction of the beach fill and to a short life of the intervention, which in turn would determine loss of public money and trouble to stakeholders and the population.

\section{Regional setting}

Marina di Pisa (Italy) is a small coastal village $11 \mathrm{~km}$ west of the city of Pisa, located along the southern sector of the Ligurian Sea (Fig. 1a). Lots of citizens from the nearby areas gather there during the summer because it is easily accessible and full of facilities and summer resorts, even though the natural sandy beaches that used to characterize the area had been almost completely wiped out by strong erosion processes. During the last 80 years this sector of the Tuscany coast has been subjected to a huge retreat, whose main reasons have to be ascribed to the harsh load decrease of the major sediment source, the River Arno (Fig. 1a). At the beginning the right side of the River Arno's delta was not protected, leading to a land loss of more than $1 \mathrm{~km}$ in less than 50 years (Aminti et al., 2000; Pranzini, 2001). The left side underwent almost immediate defense interventions (breakwaters, sea walls, and later groynes) to protect the buildings of Marina di Pisa, because the erosion processes quickly eroded the wide beaches (about $300 \mathrm{~m}$ ) and began striking the littoral promenade. In an attempt to increase tourism attraction and coast safety, during the last 15 years the local authorities created a series of artificial pebble beaches using waste from marble
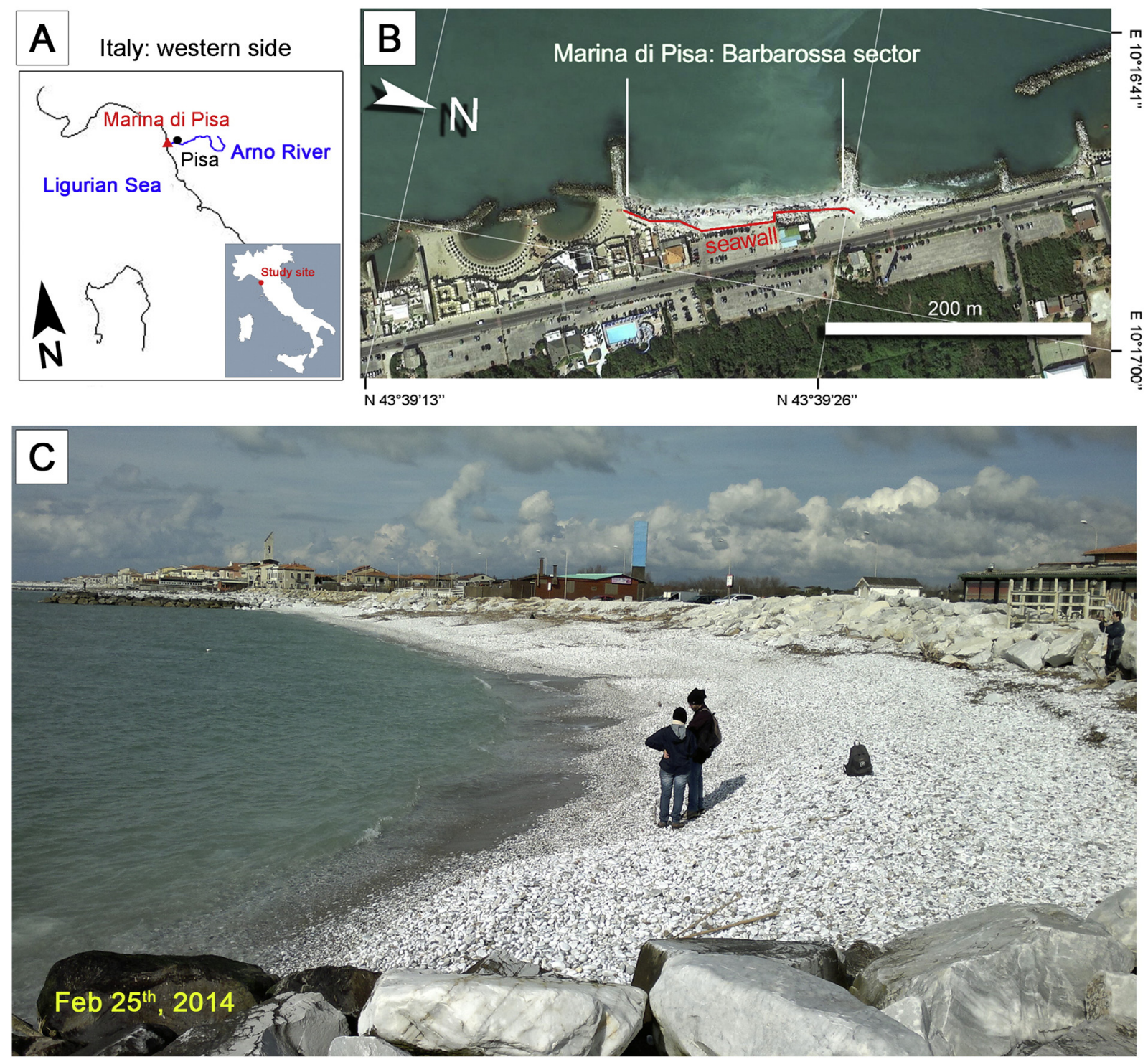

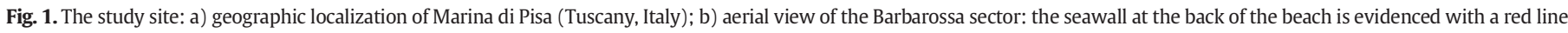

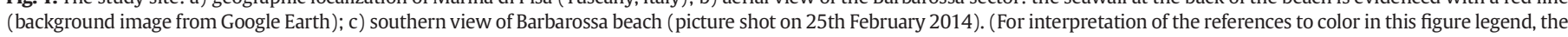
reader is referred to the web version of this article.) 
quarries. Being confined by groynes at both edges, these beaches represented the ideal setting for a sediment tracing experiment (Fig. 1b). The beach where the marked pebbles were actually injected is named Barbarossa: it is $180 \mathrm{~m}$ long and about 10 to $25 \mathrm{~m}$ wide (Fig. 1c). It is composed of a body of marble pebbles of about 30-to-90 mm in mean diameter, lying over the native sandy bed. Barbarossa beach is bounded by two groynes made of large boulders, and by a seawall that separates the backshore from summer resort facilities. The steepness is significant on the beachface (about 19\%; Bertoni and Sarti, 2011); it gets gentler offshore, reaching the typical value of this portion of the Ligurian Sea (1\%; Cipriani et al., 2001). The most frequent incident wave direction is from the southwest, as major storms are usually driven by southwesterly winds (Cipriani et al., 2001). The maximum tidal range is very low, hardly over $30 \mathrm{~cm}$ (microtidal environment). The littoral drift is directed southwards throughout this sector of the coast (Gandolfi and Paganelli, 1975), however, the groynes prevent any influence on the beach (Bertoni et al., 2012b).

\section{Materials and methods}

The pebbles were traced using the Radio Frequency Identification Technology (RFID), which is a reliable method to mark and identify individual samples. This technique has already been successfully employed on coastal settings either on the subaerial environment (Allan et al., 2006; Curtiss et al., 2009) and underwater (Bertoni et al., 2010; Grottoli et al., 2015). The RFID technology consists of an antenna (reader) transmitting a continuous low frequency radio signal $(125 \mathrm{kHz})$ to detect a transponder (tag), which has previously been inserted into a pebble and it is univocally identified by a code. The tracers were prepared for injection according to the procedure described in Bertoni et al. (2010). The 240 samples used for the experiment were randomly collected on Barbarossa beach: the only control factors were $i$ ) the size and $i$ ) the roundness. $i$ ) Pebbles with the baxis shorter than $50 \mathrm{~mm}$ were discarded because they would have likely been broken during drilling operations to insert the transponder. ii) Two populations of pebbles were collected sorted by the roundness: 120 samples were angular and representative of the sediments that were originally used to fill the beach; 120 samples were rounded and representative of the pebbles that already underwent abrasion processes on the beach. Each pebble was weighed with a digital scale $(0.1 \mathrm{~g}$ of instrument error); the three axes (a, b, c) were measured with a caliper (sensu Zingg, 1935). Both populations maintained similar characteristics in terms of average b-axis length (rounded: $88.4 \mathrm{~mm}$; angular: $97.2 \mathrm{~mm}$ ) and of average dry weight (rounded: $854.9 \mathrm{~g}$; angular: $888.6 \mathrm{~g}$ ). Since the density of the marble pebbles can be assumed as constant (about $2700 \mathrm{~kg} / \mathrm{m}^{3}$ ), hereafter we refer to volume loss (\%) instead of weight loss (\%).

The tracers were injected on the beach along 40 transects orthogonal to the coastline on November 14th, 2013. Pairs of rounded and angular pebbles were placed on three spots along each transect in accordance with the scheme described in Bertoni et al. (2012b): specifically, the crest of the fair-weather berm, the swash zone, and the crest of the step. Each pair of tracers was selected beforehand in order to select rounded and angular pebbles of similar volume and shape. The marked pebbles were accommodated among the surface sediments and not just laid on the beachface. The injection position of each tracer was recorded by a DGPS-RTK instrument, as well as the recovery position. The recovery campaigns were carried out after 3, 8, 10 and 13 months to cover a 1 -year timespan. Dry weight and axis length of the tracers that were detected and retrieved were measured with the same scale and caliper to enable comparisons to the initial measurements. The pebbles that were recovered were not injected back.

Topographic surveys of Barbarossa beach were also carried out during pebble injection and recovery activities. The surveys, performed by means of a DGPS-RTK instrument, were crucial to monitor the geomorphological evolution of the beach. The resulting data were matched with injection and recovery positions of the tracers to build consecutive maps of marked pebbles displacement using ArcGIS software applications.

\section{Results}

At the end of the time frame of the experiment (13 months) the recovery percentage was not particularly high (14\%), even though it slightly increased after each campaign (Table 1). As a whole, only 33 tracers were retrieved: 16 rounded pebbles and 17 angular pebbles. Two of the 16 rounded tracers were found clearly broken, therefore their data were discarded. Though the recovery percentage was below optimal, the volume loss measured on the pebbles that were collected was, on one hand, of remarkable magnitude (Table 2) and also showed small variation. The tracers underwent an impressive evolution in shape and roundness (Fig. 2): even though the angular pebbles showed major modifications, their volume loss is comparable to that of the rounded pebbles (Table 2 ). The bulk of the tracers (20 pieces) were detected on the backshore, between the beachface and the base of the large storm berm that formed towards the seawall at the back of the beach (Fig. 3a). Eight pebbles were found on the upper portion of the backshore, which is characterized by a large storm berm formed during the strongest storms. Very few (3) pebbles were recovered underwater. As the topographic surveys clearly indicate (Fig. 3b), Barbarossa beach underwent significant modifications: the width generally decreased by $3 \mathrm{~m}$ on the average throughout the entire length and accordingly, the steepness increased by approximately $6 \%$. The topographic variations were particularly evident on the lower backshore (Fig. 3a): each survey showed substantial adjustments due to the generation of new storm berms after subsequent high-energy events. The large storm berm towards the seawall widened between tracer injection and the second recovery campaign, but it did not experience any major modification during the summer; conversely, the storm berm got steeper in December 2014, reaching the highest height ( $3 \mathrm{~m})$.

\section{Discussion}

The unexpectedly low recovery rate was probably determined by the strong, lengthy storms occurred during the time frame of the experiment, especially in the first months (Fig. 3c): in particular, the intense storm occurred after just 6 days (20 November 2013) caused a profound reworking of the area where the pebbles were injected (Fig. 3a). As experienced in other works (Allan et al., 2006; Dickson et al., 2011; Bertoni et al., 2012b), another reason accountable for the low recovery rate might be the burial of marked pebbles under the $40 \mathrm{~cm}$ detection range of the RFID antenna, especially in the storm berm or in the underwater portion of the beach. In a tracing experiment carried out on the same beach in 2009 (Bertoni et al., 2012b), the recovery percentage exceeded 50\% after 2 months, but the storms occurred in that timespan were shorter in duration than that of November 2013. Based on the recovery of two broken pebbles and of a marble cap used to plug the transponder, breakage was likely an additional factor that led to such limited recovery rate: the series of high-energy events occurred in that timespan likely increased the probability of violent collisions between the clasts. While powerful waves determine an increase of broken pebbles, still it is not possible to evaluate whether they are responsible of the utmost wearing of the sediments, considering that

Table 1

Pebbles retrieved after each recovery campaign.

\begin{tabular}{lllllll}
\hline & 3 months & 8 months & 10 months & 13 months & Total & Recovery (\%) \\
\hline Recovered & 5 & 7 & 10 & 11 & 33 & $14 \%$ \\
Rounded & 1 & 4 & 4 & 7 & 16 & $13 \%$ \\
Angular & 4 & 3 & 6 & 4 & 17 & $14 \%$
\end{tabular}


Table 2

Average volume loss measured on the pebbles that were recovered, sorted by rounded and angular. Broken pebbles were not considered.

\begin{tabular}{|c|c|c|c|c|}
\hline Volume loss (\%) & 3 months & 8 months & 10 months & 13 months \\
\hline \multirow[t]{7}{*}{ Rounded } & - & 17,8 & 25,6 & 56,1 \\
\hline & - & 9,9 & 59,3 & 59,3 \\
\hline & - & 28,5 & 5,8 & 64,1 \\
\hline & - & 37,4 & - & 43,9 \\
\hline & - & - & - & 65,6 \\
\hline & - & - & - & 60,9 \\
\hline & - & - & - & 64,9 \\
\hline Average loss (\%) & - & 23,4 & 30,2 & 59,3 \\
\hline \multirow[t]{6}{*}{ Angular } & 23,8 & 28,0 & 41,5 & 77,2 \\
\hline & 15,5 & 32,3 & 66,4 & 71,6 \\
\hline & 11,6 & 29,5 & 18,9 & 51,9 \\
\hline & 28,4 & - & 48,4 & 56,0 \\
\hline & - & - & 10,2 & - \\
\hline & - & - & 23,8 & - \\
\hline Average loss (\%) & 19,8 & 29,9 & 34,9 & 64,2 \\
\hline Total average loss (\%) & 19,8 & 26,2 & 33,3 & 61,0 \\
\hline
\end{tabular}

significant pebble displacement is expected also during fair-weather periods (Bertoni et al., 2013).

The impressive abrasion rate (an average of more than $60 \%$ after 13 months) observed in this experiment is the sum of pebble friction and collisions due to wave motion under high-energy and low-energy conditions: just 4 tracers showed a volume loss less than $20 \%$ after 8 months. Those tracers were recovered on the crest of the storm berm, about $2 \mathrm{~m}$ above mean sea level: they underwent little wear because once they were transported to such level on the beach, they did not experience any further transport process since waves with lower energy could not reach the highest storm berms.

The considerable modifications the backshore underwent during the time frame of the experiment are an additional aspect that can possibly explain such a scant recovery rate. The storms occurred during the first interval (November 2013 - February 2014) concurred to increase size and height of the highest storm berm, which showed an evident accumulation towards the seawall especially in the central-northern portion of the beach (Fig. 3b). Several tracers might have been pushed landward and buried during the formation of the storm berms. During the second interval (February 2014 - July 2014) only one strong storm occurred, followed by a series of mild high-energy events. As a result, the storm berm was characterized by a different evolution: the crest height slightly decreased, while the base widened as a terrace about $9 \mathrm{~m}$ wide formed in the central sector of the beach. Apparently, the scour at the base of the storm berm might have determined the collapse of the high crest and a consequent accumulation in the mid-section of the backshore. The absence of relevant high-energy events during the summer (third interval: July 2014 - September 2014) did not prevent significant modifications of the middle and low portions of the backshore (Fig. 3a), confirming that low-to-mild wave states do produce remarkable adjustments (Bertoni et al., 2013; Grottoli et al., 2015): even though they involved mainly the surface layers of pebbles (Dornbusch et al., 2003), these morphologic changes allowed to recover several tracers. The role of low-energy states and fair-weather periods is not negligible for pebble abrasion: as already stated by Chen and Stephenson (2015) there is an "abrasion zone" on coarse-clastic beaches roughly corresponding to the swash zone, which is always active, and its landward extension depends on wave energy.

The last interval (September 2014 - December 2014) was characterized by a succession of storms that once again concurred to move the pebbles towards the seawall, resulting in the formation of a steep storm berm. The mobilization of the entire backshore led to the extensive reworking of the sediments, which helped unearthing several marked pebbles, whose abrasion rates were highest among all the recovered tracers.

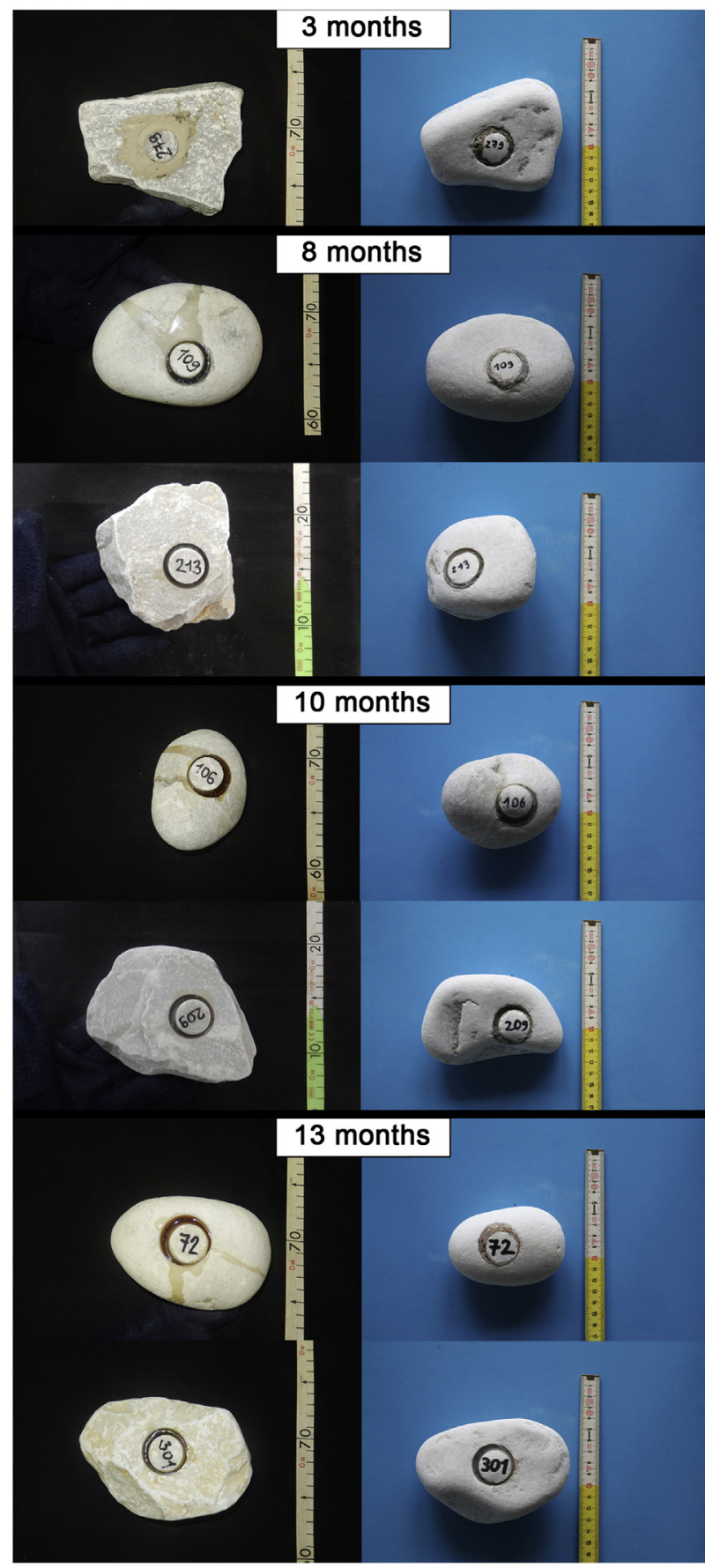

Fig. 2. Pairs of marked pebbles showing shape and roundness variations during each time interval (left column: initial configuration; right column: post-recovery configuration). Pairs of rounded and angular tracers are shown for each recovery campaign, except for the first campaign because the only rounded pebble that was recovered was discarded as it was clearly broken.

\section{Conclusions}

The tracing experiment carried out at Barbarossa beach (Marina di Pisa, Italy) within a 13-months timespan showed that sediment roundness does not affect the abrasion rate of pebbles: angular and rounded tracers recorded comparable volume losses within each time interval. This observation is in accordance with theoretical predictions (Domokos and Gibbons, 2012). The most widely applied empirical model for volume evolution during pebble abrasion is due to Sternberg stating that the abrasion rate $d V / d t$ is proportional to the volume $V$ of the pebble itself (Sternberg, 1875). This model also suggests that shape 

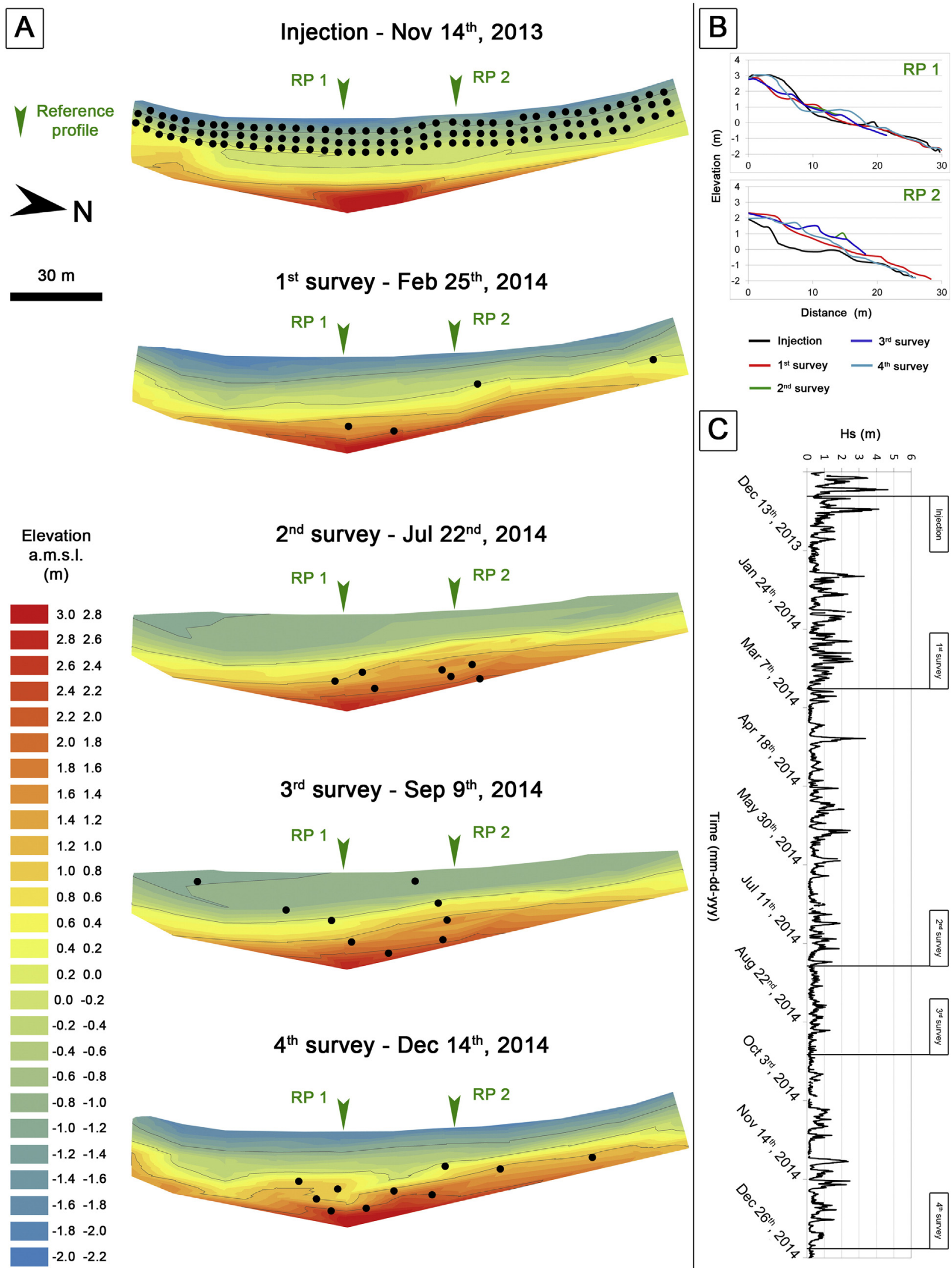

$$
\text { (1) }
$$

$$
\begin{aligned}
& - \text { Injection } \quad-3^{\text {rd }} \text { survey } \\
& -1^{\text {st }} \text { survey } \quad-4^{\text {th }} \text { survey } \\
& -2^{\text {nd }} \text { survey }
\end{aligned}
$$

C

Hs (m)

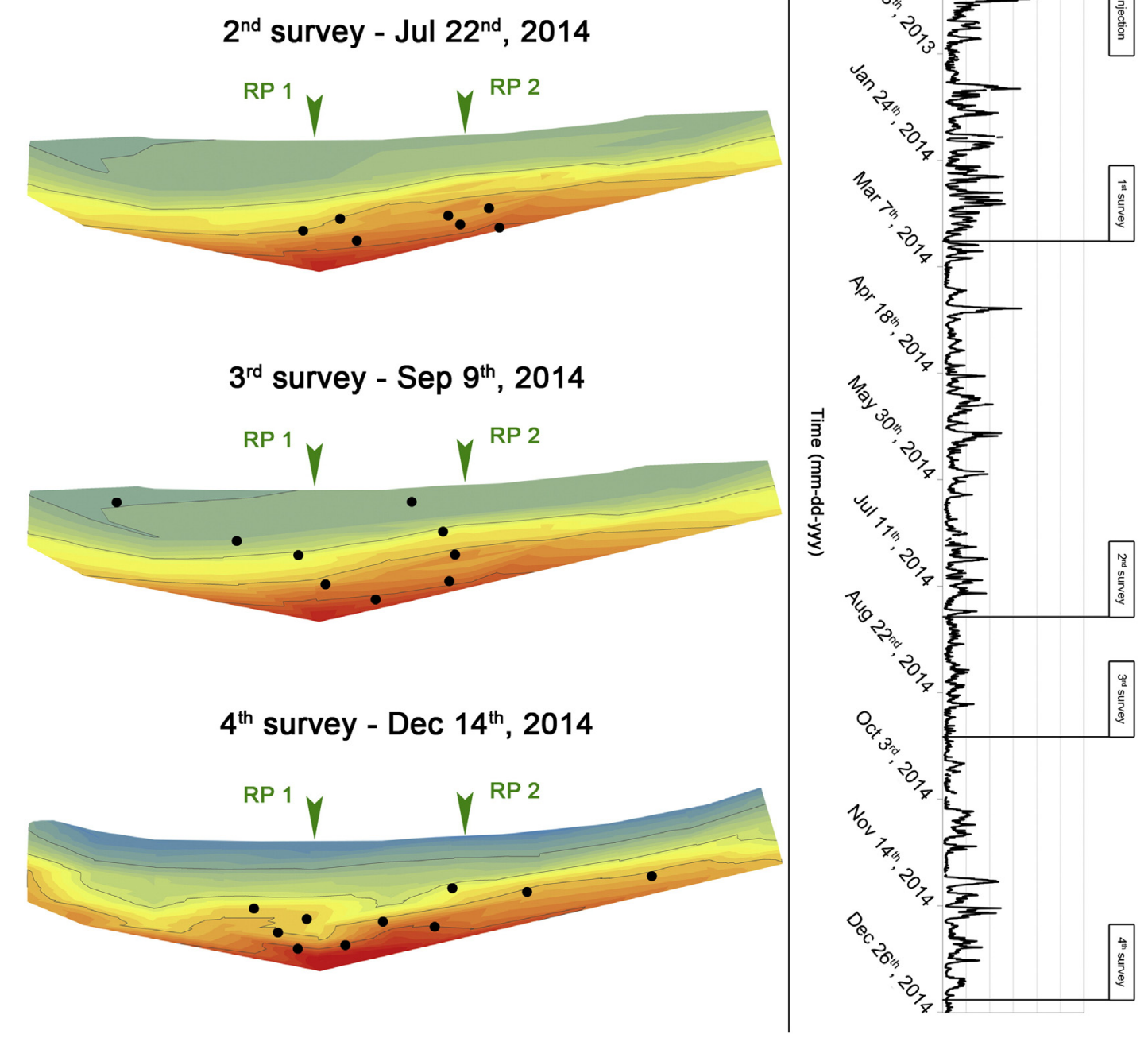

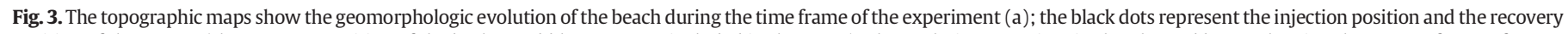

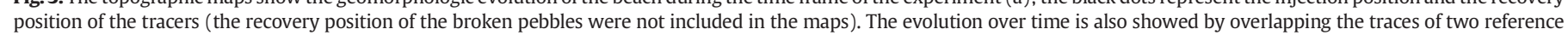
profiles, RP1 and RP2 (b). Plot showing wave height during the time frame of the experiment (c); wave data were provided by the Regional Hydrological Service. 
does not play a key role in abrasion rate, however, as the volume of the pebble decreases, abrasion rate also decreases. Since recovered pebbles were not injected back, this model cannot be verified with the current set of data.

The pebbles that did not display such high volume loss at any recovery campaign were found on the higher level of the backshore, on the top of the storm berm crest, where mechanical and chemical abrasions are negligible because wave action is active there only during major storms. Considering the environmental implications, the chemical dissolution exerted by sea water on the pebbles needs to be fully investigated: coarse-sediment beach nourishments are often realized where bathing is a key resource for tourism activities and for the economy of the coastal areas, therefore sea water quality requires to be adequately monitored immediately after the replenishment, when abrasion is supposed to be highest. Arguably, abrasion shall slow down as rounding of the clasts has taken place. In this sense, marble would not be the appropriate lithology, because is a soft rock and abrades quickly. It is still not clear whether dissolved calcium carbonate affects negatively the water quality and/or accumulates preferentially somewhere. A harder lithology may be an option: however, marble quarries are so close to Marina di Pisa, whereas sources for harder rocks are more distant (if present). The costs of using a different lithology may be so high that it could likely exceed the costs of projecting integrations to the original nourishment. Furthermore, a change in lithology would change sand color as well as the beach appearance overall. For users beach aesthetic is an important aspect which cannot be overlooked.

Barbarossa is a compartmentalized beach where the main morphological changes, in the absence of large tidal excursions and longshore currents, are caused by storms. It is quite intuitive that the continuous reworking of sediments due to tidal cycles on open beaches, as already found by Dornbusch et al. (2003), can increase the abrasion rate. Nevertheless, in such small and confined beaches as Barbarossa, the reworked bulk of sediments, which is prevented from leaving the system, is always the same. Thus, the abrasion rate in this kind of beaches is clearly exacerbated and should be a primary factor to be taken into account during the planning stages of a nourishment. Since abrasion rate of angular and rounded pebbles was comparable and consistent after each survey, our results are worth of consideration even though the number of recovered pebbles is scarce. We also remark that our data has been recorded on individually identified pebbles and not by a statistical measurement or laboratory test, so coastal managers should not neglect the volume loss recorded on the marked pebbles used for this experiment. An aspect that still needs further investigation is the time development of the abrasion process. There is currently no evidence if the process would slow down with time, with the shape of the clasts reaching an equilibrium roundness level. In conclusion, the abrasion rate needs to be considered as one of the most critical factor controlling volume loss of coarse-sediment beach nourishments.

\section{Acknowledgements}

We are grateful to many friends and colleagues that helped us out at various stages of the experiment: Dario Pacini and Giovanni Salcioli for laboratory activities; Fernanda Alquini, Alessandro Da Mommio, Debora Guerzoni, Matteo Ruocco and Sarolta Bodor during the fieldwork. Wave measurements were kindly provided by the Regional Hydrological Service (Tuscany). Many thanks to an anonymous reviewer, whose comments led to substantial improvements of the quality of this paper. GD and TNSZ acknowledge the support of Hungarian NKFIH grant K 119245. Travel and accommodation expenses in Italy for TNSZ were supported by Hungarian grant TAMOP-4.2.2.B-10/1-2010-0009.

\section{References}

Allan, J.C., Hart, R., Tranquilli, J.V., 2006. The use of passive integrated transponder (PIT) tags to trace cobble transport in a mixed sand-and-gravel beach on the high-energy Oregon coast, USA. Mar. Geol. 232, 63-86.

Aminti, P., Cipriani, L.E., Pranzini, E., 2000. Back to the Beach: Converting Seawalls into Gravel Beaches. Proceedings of the First International Soft Shore Protection Conference, Patras, Greek, pp. 187-196.

Bertoni, D., Sarti, G., 2011. On the profile evolution of three artificial pebble beaches at Marina di Pisa, Italy. Geomorphology 130, 244-254.

Bertoni, D., Sarti, G., Benelli, G., Pozzebon, A., Raguseo, G., 2010. Radio frequency identification (RFID) technology applied to the definition of underwater and subaerial coarse sediment movement. Sediment. Geol. 228, 140-150.

Bertoni, D., Sarti, G., Benelli, G., Pozzebon, A., Raguseo, G., 2012a. Transport trajectories of "smart" pebbles on an artificial coarse-grained beach at Marina di Pisa (Italy): implications for beach morphodynamics. Mar. Geol. 291-294, 227-235.

Bertoni, D., Sarti, G., Benelli, G., Pozzebon, A., 2012b. In situ abrasion of marked pebbles on two coarse-clastic beaches (Marina di Pisa, Italy). Ital. J. Geosci. 131, 205-214.

Bertoni, D., Grottoli, E., Ciavola, P., Sarti, G., Benelli, G., Pozzebon, A., 2013. On the displacement of marked pebbles on two coarse-clastic beaches during short fair-weather periods (Marina di Pisa and Portonovo, Italy). Geo-Mar. Lett. 33, 463-476.

Bigelow, G.E., 1988. Laboratory study of the role of seawater in basalt pebble abrasion. J. Coast. Res. 4, 103-113.

Chen, B., Stephenson, W., 2015. Measuring pebble abrasion on a mixed sand and grave beach using abrasion baskets. Geomorphology 248, 24-32.

Cipriani, L.E., Ferri, S., Iannotta, P., Paolieri, F., Pranzini, E., 2001. Morfologia e dinamica dei sedimenti del litorale della Toscana settentrionale. Studi Costieri 4, 119-156.

Curtiss, G.M., Osborne, P.D., Horner-Devine, A.R., 2009. Seasonal patterns of coarse sediment transport on a mixed sand and gravel beach due to vessel wakes, wind waves, and tidal currents. Mar. Geol. 259, 73-85.

Dickson, M.E., Kench, P.S., Kantor, M.S., 2011. Longshore transport of cobbles on a mixed sand and gravel beach, southern Hawke Bay, New Zealand. Mar. Geol. 287, 31-42.

Domokos, G., Gibbons, G.W., 2012. The evolution of pebble size and shape in space and time. Proc. R. Soc. Lond. A http://dx.doi.org/10.1098/rspa.2011.0562.

Dornbusch, U., Williams, R., Robinson, D., Moses, C.A., 2002. Life expectancy of shingle beaches: measuring in situ abrasion. J. Coast. Res. Spec. Issue 36, 249-255.

Dornbusch, U., Robinson, D.A., Williams, R.B.G., Moses, C.A., 2003. Estimation of Abrasion on Flint Shingle Beaches in East Sussex, UK. Proceedings of the International Conference on Coastal Sediments 2003, Clearwater Beach, Florida, pp. 18-23.

Gandolfi, G., Paganelli, L., 1975. Il litorale pisano-versiliese (Area campione Alto Tirreno). Boll. Soc. Geol. Ital. 94, 1273-1295.

Grottoli, E., Bertoni, D., Ciavola, P., Pozzebon, A., 2015. Short term displacements of marked pebbles in the swash zone: focus on particle shape and size. Mar. Geol. 367, 143-158.

Latham, J.P., Hoad, J.P., Newton, M., 1998. Abrasion of a series of tracer materials on a gravel beach, Slapton Sands, Devon, UK. In: Latham, J.P. (Ed.), Advances in Aggregates and Armourstone Evaluation 13. Engineering Geology Special Publications, Geological Society, London, pp. 121-135.

Lewin, J., Brewer, P.A., 2002. Laboratory simulation of clast abrasion. Earth Surf. Process. Landf. 27, 145-164.

Marshall, P., 1927. The wearing of beach gravels. Transactions of the Royal Society of New Zealand 58, 507-532.

Nordstrom, K.F., Pranzini, E., Jackson, N.L., Coli, M., 2008. The marble beaches of Tuscany. Geogr. Rev. 98, 280-300.

Pranzini, E., 2001. Updrift river mouth migration on cuspate deltas: two examples from the coast of Tuscany (Italy). Geomorphology 38, 125-132.

Russell, R.D., 1939. Effects of transportation of sedimentary particles. In: Trask, P.D. (Ed.) Recent Marine Sediments. Tulsa (Oklahoma), The Society of Economic Paleontologists and Mineralogists, pp. 32-47.

Sternberg, H., 1875. Untersuchungen über Langen- und Querprofil geschiebeführender Flüsse. Zeitschrift für Bauwesen 25, 483-506.

Szabò, T., Fityus, S., Domokos, G., 2013. Abrasion model of downstream changes in grain shape and size along the Williams River, Australia. J. Geophys. Res. Earth Surf. 118 2059-2071.

Zingg, T., 1935. Beitrag zur Schotteranalyse. Schweiz. Mineral. Petrogr. Mitt. 15, 39-140. 